TITLE:

\title{
Formation of Nickel Nanowires via Electroless Deposition Under a Magnetic Field
}

$\operatorname{AUTHOR}(S)$ :

Kawamori, Makoto; Yagi, Shunsuke; Matsubara, Eiichiro

\section{CITATION:}

Kawamori, Makoto ... [et al]. Formation of Nickel Nanowires via Electroless Deposition Under a Magnetic Field. Journal of The Electrochemical Society 2011, 158(8): E79-E83

\author{
ISSUE DATE: \\ 2011-06 \\ URL: \\ http://hdl.handle.net/2433/155959 \\ RIGHT: \\ (C)2011 The Electrochemical Society.
}




\title{
Formation of Nickel Nanowires via Electroless Deposition Under a Magnetic Field
}

\author{
Makoto Kawamori, ${ }^{*, z}$ Shunsuke Yagi, ${ }^{* *, a}$ and Eiichiro Matsubara \\ Department of Materials Science and Engineering, Kyoto University, Kyoto 606-8501, Japan
}

Nickel nanowires were synthesized via electroless deposition in an organic solvent (ethylene glycol) under a magnetic field. Deposition behavior of nickel particles and wires were electrochemically investigated at various concentrations of $\mathrm{NaOH}$ by an in-situ mixed potential measurement and voltammetry combined with quartz crystal microbalance. Based on the electrochemical investigation, a formation mechanism of nickel wires is proposed. According to the mechanism, nickel wires 100-370 nm in diameter with several dozen $\mu \mathrm{m}$ of length were successfully prepared by controlling the reduction rate by varying a concentration of sodium hydroxide, trisodium citrate, and a nucleating agent, chloroplatinic acid.

(C) 2011 The Electrochemical Society. [DOI: 10.1149/1.3596703] All rights reserved.

Manuscript submitted March 18, 2011; revised manuscript received May 10, 2011. Published June 10, 2011.

Nanowires of iron group metals $(\mathrm{Fe}, \mathrm{Co}, \mathrm{Ni})$ and their alloys are attractive materials due to their magnetic properties. ${ }^{1,2}$ Numerous synthesis methods of iron group nanowires have been reported. ${ }^{3-8}$ In their methods, nanowires are formed by electrodeposition using templates such as anodized aluminum oxide ${ }^{3-5}$ and polycarbonate membrane. ${ }^{6-8}$ The methods with templates have notable advantages that highly-ordered and size-controlled nanowires can be obtained. The template methods, however, require several steps including fabrication and removal of templates in order to obtain bare nanowires. On the other hand, a self-assemble electroless deposition of ferromagnetic nanowires under a magnetic field is a relatively simple synthesis method without any templates. ${ }^{9}$ In addition, electroless deposition is a powerful fabrication method with a wide variety of compositions and sizes in a large-scale $\mathrm{e}^{10,11}$ and thus, electroless deposition is suitable for a practical application.

We have reported some studies of electrochemical approaches with in-situ mixed potential observation for the synthesis processes of copper, ${ }^{12,13}$ cobalt,${ }^{14,15}$ nickel, ${ }^{16}$ and Co-Ni alloy ${ }^{17}$ nanoparticles, which is effective in thermodynamic oxidation-state control and analysis of the formation process of nanowires as well as nanoparticles. In the present work, the formation process of nickel nanowires via electroless deposition under a magnetic field was electrochemically investigated. In order to control the morphology of nickel deposits, the deposition behavior of nickel was studied by an in-situ mixed potential measurement; it is possible that the reduction rate of $\mathrm{Ni}$ (II) species affects the morphology of nickel deposits. Furthermore, the reduction rate and reduction potential of $\mathrm{Ni}$ (II) species were investigated by voltammetry combined with quartz crystal microbalance (QCM) as well as the oxidation rate and oxidation potential of hydrazine as a counterpart reaction.

\section{Experimental}

The reaction solutions were prepared using nickel chloride hexahydrate $\left(\mathrm{NiCl}_{2} \cdot 6 \mathrm{H}_{2} \mathrm{O}\right)$ as a source of $\mathrm{Ni}(\mathrm{II})$ ions, ethylene glycol (EG) as a solvent, and hydrazine monohydrate $\left(\mathrm{N}_{2} \mathrm{H}_{4} \cdot \mathrm{H}_{2} \mathrm{O}\right)$ as a reducing agent. Sodium hydroxide $(\mathrm{NaOH})$ was added as a source of $\mathrm{OH}^{-}$ions. Trisodium citrate dihydrate $\left(\mathrm{Na}_{3} \mathrm{C}_{6} \mathrm{H}_{5} \mathrm{O}_{7} \cdot 2 \mathrm{H}_{2} \mathrm{O}\right)$ and chloroplatinic acid hexahydrate $\left(\mathrm{H}_{2} \mathrm{PtCl}_{6} \cdot 6 \mathrm{H}_{2} \mathrm{O}\right)$ were used as a complexing agent and a nucleating agent, respectively. These reagents are all reagent-grade (Nacarai Tesque, Inc.) and used without further purification.

First, $27 \mathrm{~cm}^{3}$ EG solution containing $0.100 \mathrm{M} \mathrm{NiCl}_{2}, 0.2-1.4 \mathrm{M}$ $\mathrm{NaOH}$, and 0-10.0 mM Na $\mathrm{C}_{6} \mathrm{H}_{5} \mathrm{O}_{7}$ was prepared, where $\mathrm{M}$ corresponds to $\mathrm{mol} \mathrm{dm} \mathrm{dm}^{-3}$. For experiments with a nucleating agent, $\mathrm{H}_{2} \mathrm{PtCl}_{6}(0.02-2.00 \mathrm{mM})$ was added as a nucleating agent. The

\footnotetext{
* Electrochemical Society Student Member.

** Electrochemical Society Active Member.

a Present address: Nanoscience and Nanotechnology Research Center, Osaka Prefecture University, Osaka 599-8570, Japan.

z E-mail:kawamori@makoto.mbox.media.kyoto-u.ac.jp
}

same amount of EG solution $\left(27 \mathrm{~cm}^{3}\right)$ containing $1.00 \mathrm{M} \mathrm{N}_{2} \mathrm{H}_{4}$, $0-0.6 \mathrm{M} \mathrm{NaOH}$, and $0-10.0 \mathrm{mM} \mathrm{Na}_{3} \mathrm{C}_{6} \mathrm{H}_{5} \mathrm{O}_{7}$ was also prepared. The compositions of reaction solutions are summarized in Table I. The temperature of the solutions was kept at $353 \mathrm{~K}$ with nitrogen gas bubbling to remove the dissolved oxygen. The metallic salt solution and the hydrazine solution were mixed at $353 \mathrm{~K}$ to start the reaction. The reaction solution was agitated at a rate of $500 \mathrm{rpm}$ with a magnetic stirring unit at $353 \mathrm{~K}$ during the reaction for the synthesis of nickel particles. For the synthesis of nickel wires, the reaction solution was kept at $353 \mathrm{~K}$ in a water bath located inside the two parallel neodymium magnets $(100 \times 100 \mathrm{~mm})$ separated 100 $\mathrm{mm}$ apart. Magnetic field inside the magnets was about 100-200 $\mathrm{mT}$, which is measured by a Tesla meter (KANETEC Co., Ltd., TM-601). After the reaction, nickel particles and wires were washed several times with ethanol.

The morphology of products was observed by a field-emission scanning electron microscope (JEOL Ltd., JSM-6500F). The average diameter and size distribution of the nickel particles were determined by image analysis for randomly selected 600 particles in each sample. During the synthesis of nickel particles, a gold-sputtered QCM electrode (SEIKO EG\&G, QA-A9M-AU) was immersed in the reaction solution and the mixed potential on the QCM electrode was measured by a potentiostat/galvanostat (Hokuto Denko Co., Ltd., HA-151) using a $\mathrm{Ag} / \mathrm{AgCl}(3.33 \mathrm{M} \mathrm{KCl})$ electrode (Horiba, 2565A-10T) as a reference electrode. Cyclic voltammograms were also measured by the potentiostat/galvanostat using a nickel-sputtered QCM electrode (SEIKO EG\&G, QA-A9M-NI) as a working electrode, a platinum electrode $(20 \times 20 \mathrm{~mm})$ as a counter electrode, and a $\mathrm{Ag} / \mathrm{AgCl}$ electrode as a reference electrode. The weight of nickel deposited on the QCM electrode, $\Delta m$, was calculated from the change in resonance frequency of the QCM electrode, $\Delta f$, by Sauerbrey's equation ${ }^{18}$

$$
\Delta m=-\frac{A \sqrt{\rho_{q} \mu_{q}}}{2 f_{0}^{2}} \Delta f
$$

where $f_{0}$ is the frequency of the QCM electrode before the deposition, $A$ is the active area of the QCM electrode $\left(0.196 \mathrm{~cm}^{2}\right), \rho_{\mathrm{q}}$ is the density of quartz $\left(2.648 \mathrm{~g} \mathrm{~cm}^{-3}\right)$, and $\mu_{\mathrm{q}}$ is the shear modulus of quartz $\left(2.947 \times 10^{11} \mathrm{~g} \mathrm{~cm}^{-1} \mathrm{~s}^{-2}\right)$.

\section{Results}

Figure 1 shows the size distributions and scanning electron microscopy (SEM) images of nickel particles synthesized without a magnetic field at different concentrations of $\mathrm{NaOH}$. The size of particles increases with a decrease in a concentration of $\mathrm{NaOH}$. The average particle size is about $240 \mathrm{~nm}$ at $1.0 \mathrm{M} \mathrm{NaOH}$ and $480 \mathrm{~nm}$ at $0.1 \mathrm{M} \mathrm{NaOH}$. The size distribution becomes sharper at a higher concentration of $\mathrm{NaOH}$.

Figure 2 shows the SEM images of nickel particles and wires synthesized from the solutions under a magnetic field at different 
Table I. Compositions of hydrazine solutions for the synthesis of nickel particles and wires.

\begin{tabular}{|c|c|c|c|c|c|c|}
\hline & \multicolumn{3}{|c|}{ Compositions of metallic salt solutions } & \multicolumn{3}{|c|}{ Compositions of metallic salt solutions } \\
\hline & $\begin{array}{c}{\left[\mathrm{NiCI}_{2}\right]} \\
(\mathrm{M})\end{array}$ & $\begin{array}{c}{[\mathrm{NaOH}]} \\
(\mathrm{M})\end{array}$ & $\begin{array}{c}{\left[\mathrm{Na}_{3} \mathrm{C}_{6} \mathrm{H}_{5} \mathrm{O}_{7}\right]} \\
(\mathrm{mM})\end{array}$ & $\begin{array}{c}{\left[\mathrm{N}_{2} \mathrm{H}_{4}\right]} \\
(\mathrm{M})\end{array}$ & $\begin{array}{c}{[\mathrm{NaOH}]} \\
(\mathrm{M})\end{array}$ & $\begin{array}{c}{\left[\mathrm{Na}_{3} \mathrm{C}_{6} \mathrm{H}_{5} \mathrm{O}_{7}\right]} \\
(\mathrm{mM})\end{array}$ \\
\hline (ii) & 0.100 & 0.3 & - & 1.00 & 0.1 & - \\
\hline (iii) & 0.100 & 0.2 & - & 1.00 & - & - \\
\hline (iv) & 0.100 & 1.4 & 5.0 & 1.00 & 0.6 & 5.0 \\
\hline
\end{tabular}

concentrations of $\mathrm{NaOH}$. At $1.0 \mathrm{M} \mathrm{NaOH}$, nickel particles about $250 \mathrm{~nm}$ in diameter were obtained. Beads-like nickel wires were obtained at $0.2 \mathrm{M} \mathrm{NaOH}$. Nickel wires approximately $500 \mathrm{~nm}$ in diameter with a smooth surface were obtained at $0.1 \mathrm{M} \mathrm{NaOH}$. It should be noted that there is no large change of the each particle size with and without a magnetic field at the same concentration of $\mathrm{NaOH}$. These results also indicate that a magnetic field strongly affects the morphology of nickel.

In the present process, the following hydrazine oxidation reactions mainly occur as anodic reactions

$$
\begin{gathered}
\mathrm{N}_{2} \mathrm{H}_{4}+4 \mathrm{OH}^{-} \rightarrow \mathrm{N}_{2}+4 \mathrm{H}_{2} \mathrm{O}+4 \mathrm{e} \\
\mathrm{N}_{2} \mathrm{H}_{4}+\mathrm{OH}^{-} \rightarrow \frac{1}{2} \mathrm{~N}_{2}+\mathrm{NH}_{3}+\mathrm{H}_{2} \mathrm{O}+\mathrm{e}
\end{gathered}
$$

Figure 3 shows anodic polarization curves measured on nickel substrates in $120 \mathrm{~cm}^{3}$ EG containing $0.50 \mathrm{M} \mathrm{N}_{2} \mathrm{H}_{4}$ and $0.1-1.0 \mathrm{M}$
$\mathrm{NaOH}$. The oxidation potential of hydrazine positively shifts from -1.06 to $-0.85 \mathrm{~V}$ vs $\mathrm{Ag} / \mathrm{AgCl}$ and the slope of the anodic current density becomes smaller with the decrease in a concentration of $\mathrm{NaOH}$. The conductivity of the solution becomes lower with decreasing a concentration of $\mathrm{NaOH}$. The conductivities measured by a conductivity electrode (Horiba, 9382-10D) are 2.12, 1.27, and $0.72 \mathrm{~S} \mathrm{~m}^{-1}$ at $1.0,0.2$, and $0.1 \mathrm{M} \mathrm{NaOH}$, respectively. The large change of anodic current density at different concentrations of $\mathrm{NaOH}$ cannot be obviously explained only by the change of the solution resistance. Considering the increased ohmic drop due to the solution resistance, the slope of the I/V curve is still smaller at a lower concentration of $\mathrm{NaOH}$. In other words, the current density at a potential is smaller at a lower $\mathrm{NaOH}$ concentration. This indicates that a reduction ability of hydrazine becomes weaker at a lower concentration of $\mathrm{NaOH}$.

Both a weight of deposited metal and a total current density are simultaneously measured by voltammetry combined with QCM. The
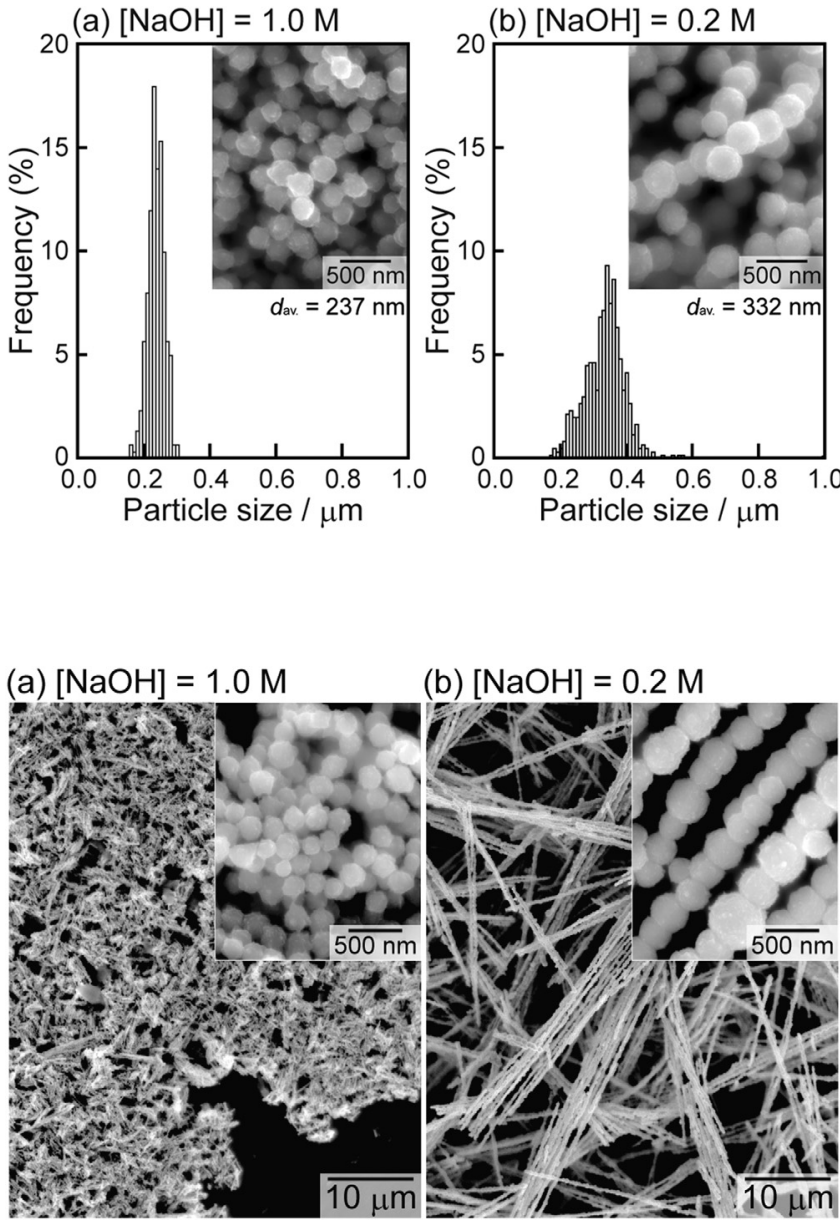

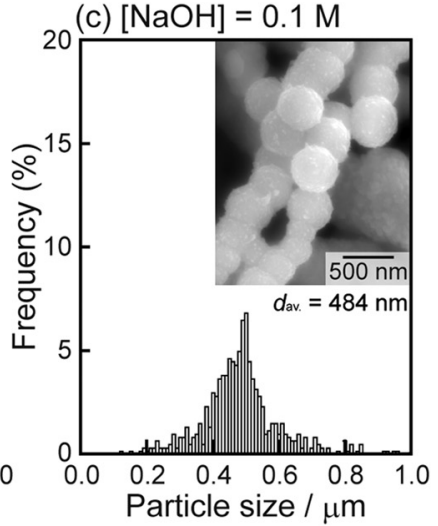

(c) $[\mathrm{NaOH}]=0.1 \mathrm{M}$

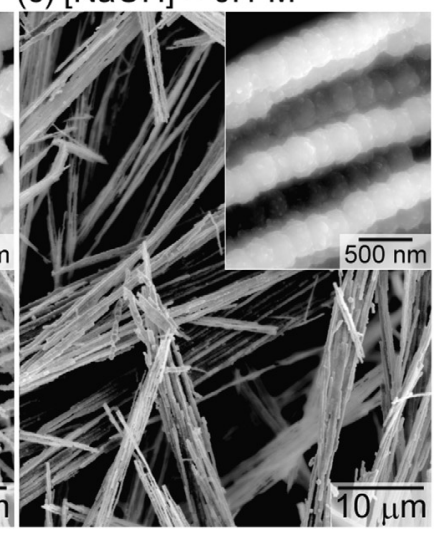

Figure 1. Size distributions and SEM images of nickel particles synthesized from solutions containing $0.050 \mathrm{M} \mathrm{NiCl}_{2}$, $0.50 \mathrm{M} \mathrm{N}_{2} \mathrm{H}_{4}$, (a) $1.0 \mathrm{M}$, (b) $0.2 \mathrm{M}$, and (c) $0.1 \mathrm{M} \mathrm{NaOH}$. Average diameter $d_{\mathrm{av}}$ is also indicated. 


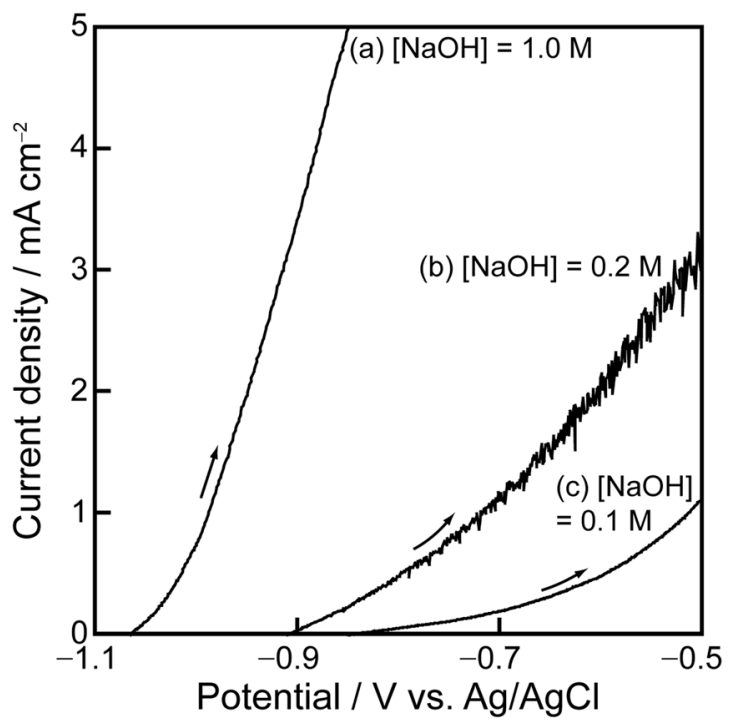

Figure 3. Anodic polarization curves measured at $1 \mathrm{mV} \mathrm{s}^{-1}$ in EG containing $0.50 \mathrm{M} \mathrm{N}_{2} \mathrm{H}_{4}$, (a) $1.0 \mathrm{M}$, (b) $0.2 \mathrm{M}$, and (c) $0.1 \mathrm{M} \mathrm{NaOH}$.

following reduction reaction of $\mathrm{Ni}$ (II) species was separately evaluated from the weight change of nickel deposited on the QCM substrate

$$
\mathrm{Ni}(\mathrm{II})+2 \mathrm{e} \rightarrow \mathrm{Ni}
$$

where $\mathrm{Ni}(\mathrm{II})$ represents all the nickel(II) species, e.g. $\mathrm{Ni}^{2+}, \mathrm{NiOH}^{+}$, $\mathrm{Ni}(\mathrm{OH})_{2}, \mathrm{HNiO}_{2}^{-}$, and $\mathrm{NiO}_{2}^{2-}$. ${ }^{19}$ The contribution of the reductive decomposition of the solvent to the total current density is dominant in this process, and the current density due to nickel deposition is hardly observed by a normal voltammetry. Figure 4 shows cyclic voltammograms measured in $120 \mathrm{~cm}^{3}$ EG containing $0.050 \mathrm{M}$ $\mathrm{NiCl}_{2}$ and 0.1-1.0 $\mathrm{M} \mathrm{NaOH}$. At 1.0 $\mathrm{M} \mathrm{NaOH}$ (Fig. 4a, dotted line), the cathodic current of hydrogen generation is observed below about $-0.80 \mathrm{~V}$ vs $\mathrm{Ag} / \mathrm{AgCl}$ during the cathodic sweep, and the oxidization current of hydrogen adsorbed on the QCM substrate is observed above $-0.87 \mathrm{~V}$. In a cyclic voltammogram drawn by QCM result (solid line), the nickel reduction was observed below about $-0.80 \mathrm{~V}$ during the cathodic sweep, and the dissolution of nickel was seen above $-0.80 \mathrm{~V}$ during the anodic sweep. Therefore, the redox potential of $\mathrm{Ni}(\mathrm{II}) / \mathrm{Ni}$ redox couple is about $-0.80 \mathrm{~V}$ vs $\mathrm{Ag} / \mathrm{AgCl}$ at $1.0 \mathrm{M} \mathrm{NaOH}$. Similarly, the redox potential of $\mathrm{Ni}(\mathrm{II}) / \mathrm{Ni}$ redox couple can be determined to be about -0.70 and $-0.45 \mathrm{~V}$ at $0.2 \mathrm{M}$

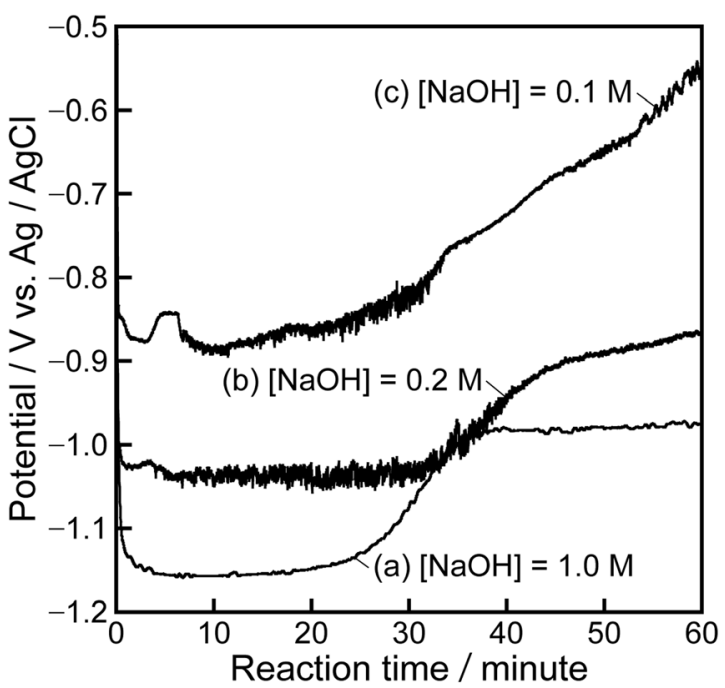

Figure 5. Time dependence of mixed potential in solutions containing 0.050 $\mathrm{M} \mathrm{NiCl}_{2}, 0.50 \mathrm{M} \mathrm{N}_{2} \mathrm{H}_{4}$, (a) $1.0 \mathrm{M}$, (b) $0.2 \mathrm{M}$, and (c) $0.1 \mathrm{M} \mathrm{NaOH}$.

and $0.1 \mathrm{M} \mathrm{NaOH}$, respectively. Therefore, it is clarified that the redox potential of $\mathrm{Ni}(\mathrm{II}) / \mathrm{Ni}$ redox couple shifts to the negative direction by increasing the concentration of $\mathrm{NaOH}$. The reduction current density of $\mathrm{Ni}(\mathrm{II})$ species is much smaller at 1.0 and $0.2 \mathrm{M}$ compared with that at $0.1 \mathrm{M} \mathrm{NaOH}$. This is because $\mathrm{Ni}$ (II) ions in the metallic salt solution were hydroxylated to form green nickel hydroxide and/ or nickel alkoxide sol by the addition of $\mathrm{NaOH}$, which results in the low current efficiency of the nickel deposition as shown in Fig. 4. An activity of $\mathrm{Ni}^{2+}$ ions decreases with an increase of the concentration of $\mathrm{NaOH}$ and the redox potential of $\mathrm{Ni}(\mathrm{II}) / \mathrm{Ni}$ shifts to the negative direction according to the Nernst equation.

Figure 5 shows the time transition in the mixed potential on the QCM substrate during the synthesis. Just after mixing the metallic salt solution and the hydrazine solution, the mixed potential rapidly dropped below the redox potentials of $\mathrm{Ni}(\mathrm{II}) / \mathrm{Ni}$ in each condition, indicating that nickel deposition is thermodynamically possible. At a lower concentration of $\mathrm{NaOH}$, the mixed potential positively shifts, which corresponds to the result that the current density of hydrazine oxidation declines with decrease in a concentration of $\mathrm{NaOH}$. An increase of potential with time can be mainly attributed to a consumption of hydrazine, because the mixed potential is mainly determined by the balance of hydrazine oxidation reactions and a decomposition of large amount of solvent.
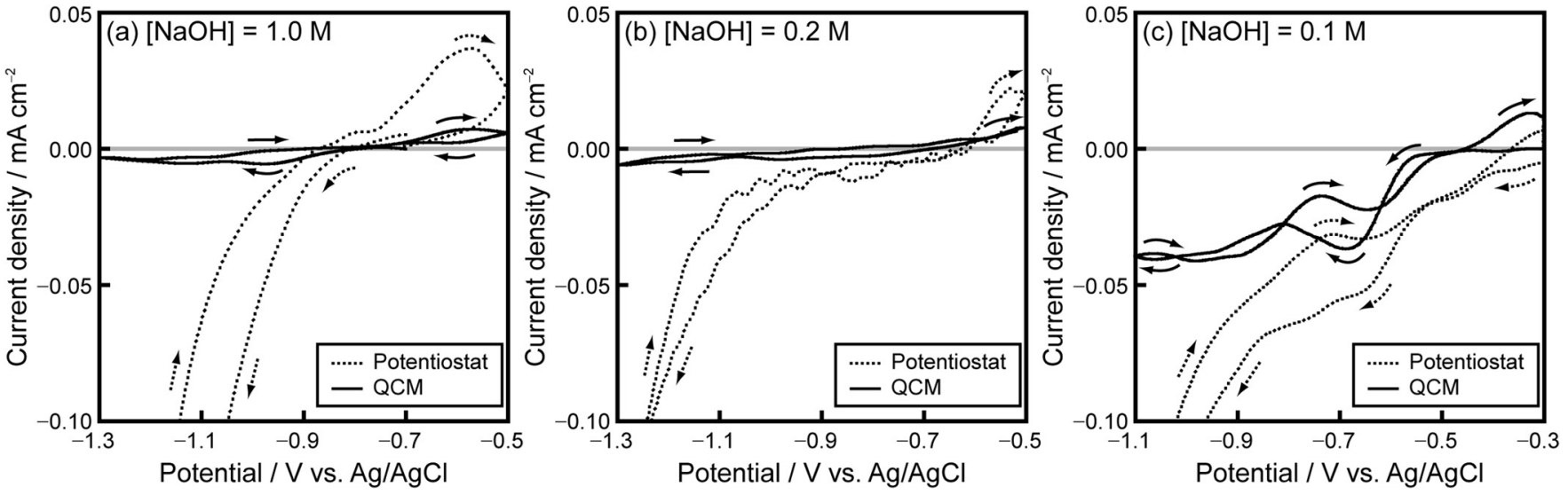

Figure 4. Cyclic voltammograms measured by potentiostat (dotted line) and QCM (solid line) at $1 \mathrm{mV} \mathrm{s}^{-1}$ in $\mathrm{EG}$ containing $0.050 \mathrm{M} \mathrm{NiCl} \mathrm{L}_{2}$, (a) $1.0 \mathrm{M}$, (b) 0.2 $\mathrm{M}$, and (c) $0.1 \mathrm{M} \mathrm{NaOH}$. 


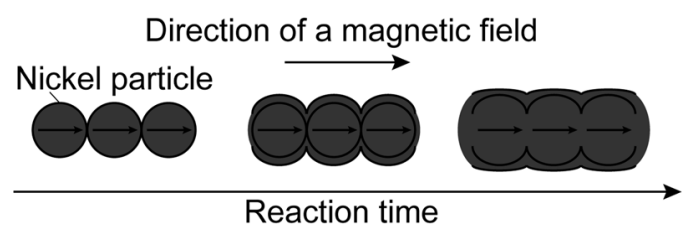

Figure 6. Schematic of the formation process of nickel wires.

\section{Discussion}

The concentration of $\mathrm{NaOH}$ significantly affects on both the hydrazine oxidation reactions and the nickel deposition reaction. With decreasing the amount of $\mathrm{NaOH}$, the reduction ability of hydrazine becomes weaker, and as a result, the mixed potential becomes higher as shown in Figs. 3 and 5. Thus, the driving force of nickel deposition tends to be larger and homogeneous nucleation of nickel is favorable at a higher concentration of $\mathrm{NaOH}$. On the other hand, the deposition current density of nickel is much smaller at $1.0 \mathrm{M}$ $\mathrm{NaOH}$ than that at $0.1 \mathrm{M} \mathrm{NaOH}$ as shown in Fig. 4, which indicates that the particle growth is suppressed at a higher $\mathrm{NaOH}$ concentration. Consequently, the finer nickel particles with a narrower size distribution are achieved at $1.0 \mathrm{M} \mathrm{NaOH}$ as shown in Fig. 1a.

The morphological change in nickel wires is explained by the formation mechanism of nickel wires schematically drawn in Fig. 6. First, nickel particles are formed in the reaction solution in the initial reaction stage, and are aligned along a magnetic field due to magnetic interaction. Then, nickel preferentially deposits at the necks between particles to decrease the interfacial energy. The particles are tightly connected and finally form rigid wires with a smooth surface. Therefore, the necessary condition for the formation of nickel wires is that the alignment of particles occurs prior to the end of the reduction reaction. At $1.0 \mathrm{M} \mathrm{NaOH}$, the reduction ability of hydrazine is so high that large amount of nickel nuclei are rapidly formed, and the nickel deposition has finished before the alignment of particles. The nickel particles are not tightly connected under a magnetic field because of their fast reduction rate at $1.0 \mathrm{M} \mathrm{NaOH}$. It is likely that the nickel wires easily broke down during washing in ethanol as shown in Fig. 2a. At a lower concentration of $\mathrm{NaOH}$, the reduction ability of hydrazine is not so high that there is enough time for the particles to align along the magnetic field and are connected by preferential deposition at the necks between them. Thus, the nickel wires are obtained at a lower concentration of $\mathrm{NaOH}$ as shown in Figs. $2 \mathrm{~b}$ and $2 \mathrm{c}$. The wires are beads-like shape at $0.2 \mathrm{M}$ $\mathrm{NaOH}$ and become smooth at $0.1 \mathrm{M} \mathrm{NaOH}$.

In order to verify this formation mechanism of nickel wires, the nickel wires were fabricated by adding a complexing agent, $\mathrm{Na}_{3} \mathrm{C}_{6} \mathrm{H}_{5} \mathrm{O}_{7}$. Generally, complexing agents such as citrate, whose complex formation constant with $\mathrm{Ni}$ (II) ions is high, are used for a control of the activity of $\mathrm{Ni}$ (II) ions and the deposition rate. ${ }^{20,21}$ Figure 7 shows the SEM images of nickel deposits synthesized from the reaction solutions containing $0.050 \mathrm{NiCl}_{2}, 0.50 \mathrm{M} \mathrm{N}_{2} \mathrm{H}_{4}$, $1.0 \mathrm{M} \mathrm{NaOH}$, and 5.0-10.0 $\mathrm{mM} \mathrm{Na}_{3} \mathrm{C}_{6} \mathrm{H}_{5} \mathrm{O}_{7}$ under a magnetic field. While nickel particles were obtained without $\mathrm{Na}_{3} \mathrm{C}_{6} \mathrm{H}_{5} \mathrm{O}_{7}$ (Fig. 2a), beads-like nickel wires whose diameter is about $320 \mathrm{~nm}$ were formed at $5.0 \mathrm{mM} \mathrm{Na}{ }_{3} \mathrm{C}_{6} \mathrm{H}_{5} \mathrm{O}_{7}$ (Fig. 7a). The surface of nickel wires becomes smoother at a higher concentration of $\mathrm{Na}_{3} \mathrm{C}_{6} \mathrm{H}_{5} \mathrm{O}_{7}$ (Figs. $7 \mathrm{~b}$ and $7 \mathrm{c}$ ). Consequently, the formation of wires becomes easier at a slower reaction rate as it is expected from the discussion above. (a) $\left[\mathrm{Na}_{3} \mathrm{C}_{6} \mathrm{H}_{5} \mathrm{O}_{7}\right]=5.0 \mathrm{mM}$

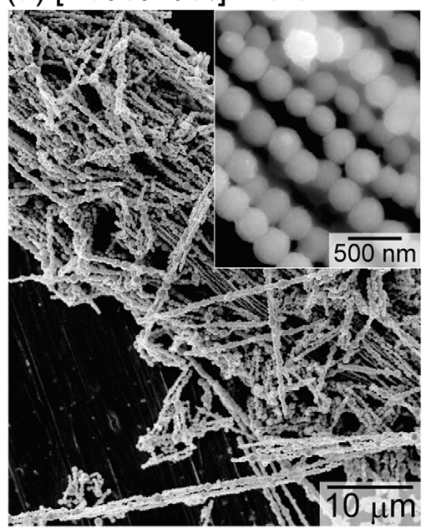

(c) $\left[\mathrm{Na}_{3} \mathrm{C}_{6} \mathrm{H}_{5} \mathrm{O}_{7}\right]=10.0 \mathrm{mM}$

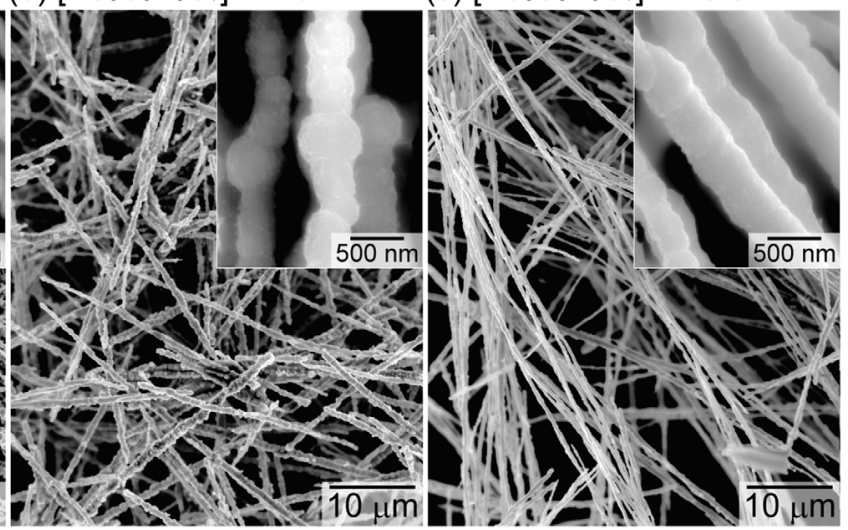

Figure 7. SEM images of nickel nanowires synthesized from solutions containing $0.050 \mathrm{M} \mathrm{NiCl}_{2}, 0.50 \mathrm{M} \mathrm{N}_{2} \mathrm{H}_{4}, 1.0 \mathrm{M}$ $\mathrm{NaOH}$, (a) $5.0 \mathrm{mM}$, (b) $7.5 \mathrm{mM}$, and (c) $10.0 \mathrm{mM} \mathrm{Na} \mathrm{C}_{6} \mathrm{H}_{5} \mathrm{O}_{7}$ under a magnetic field.

\section{(a) $\left[\mathrm{H}_{2} \mathrm{PtCl}_{6}\right]=0.01 \mathrm{mM}$}

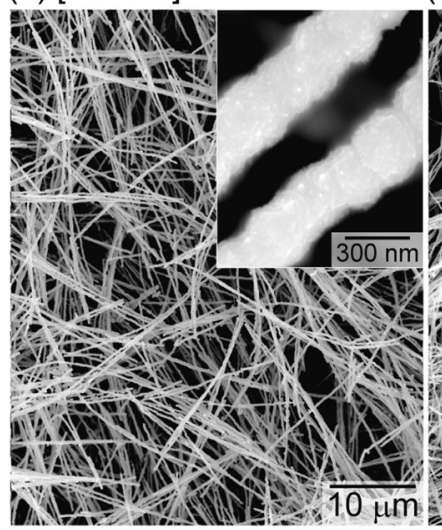

(b) $\left[\mathrm{H}_{2} \mathrm{PtCl}_{6}\right]=0.10 \mathrm{mM}$

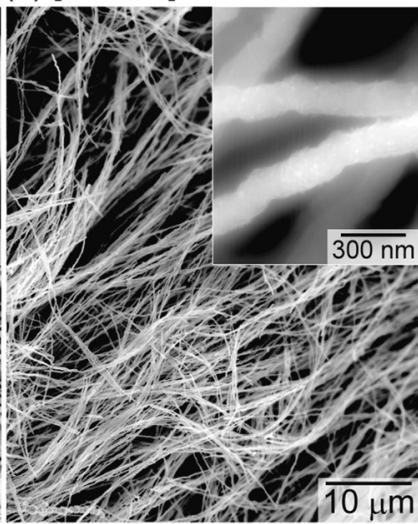

(c) $\left[\mathrm{H}_{2} \mathrm{PtCl}_{6}\right]=1.00 \mathrm{mM}$

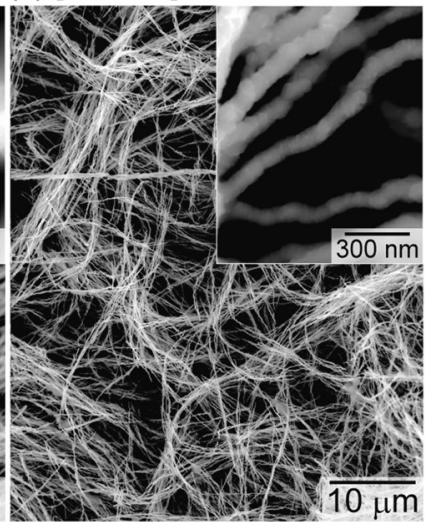

Figure 8. SEM images of nickel nanowires synthesized from solutions containing $0.050 \mathrm{M} \mathrm{NiCl}_{2}, 0.50 \mathrm{M} \mathrm{N}_{2} \mathrm{H}_{4}, 1.0 \mathrm{M}$ $\mathrm{NaOH}, 10.0 \mathrm{mM} \mathrm{Na} \mathrm{C}_{6} \mathrm{H}_{5} \mathrm{O}_{7}$, (a) 0.01 $\mathrm{mM}$, (b) $0.10 \mathrm{mM}$, and (c) $1.00 \mathrm{mM}$ $\mathrm{H}_{2} \mathrm{PtCl}_{6}$ under a magnetic field. 
In the present results, it is important that the nickel wires are formed after the formation of nickel particles. Therefore, we can apply the same size-control method as particles synthesis by electroless deposition for the diameter control of nickel wires. To control the nickel particle size, chloroplatinic acid $\left(\mathrm{H}_{2} \mathrm{PtCl}_{6}\right)$ is often used as a nucleating agent. ${ }^{22,23}$ It is considered that the nucleating agent, whose redox potential is much higher than that of the objective metal, provides many heterogeneous nucleation sites, resulting in the formation of abundant and fine particles. The formation of platinum nuclei divides the nucleation and growth stages during the formation of nickel particles, which gives us a sharper size distribution. Figure 8 shows the SEM images of nickel wires synthesized from the solutions containing $0.050 \mathrm{NiCl}_{2}, 0.50 \mathrm{M} \mathrm{N}_{2} \mathrm{H}_{4}, 1.0 \mathrm{M} \mathrm{NaOH}, 10.0 \mathrm{mM} \mathrm{Na}_{3} \mathrm{C}_{6} \mathrm{H}_{5} \mathrm{O}_{7}$, and 0.01-1.00 mM H $\mathrm{H}_{2} \mathrm{PtCl}_{6}$. The diameter of nickel wires becomes smaller with an increase in a concentration of $\mathrm{H}_{2} \mathrm{PtCl}_{6}$; the average diameters were 280,160 , and $100 \mathrm{~nm}$ at $0.01,0.10$, and $1.00 \mathrm{mM}$ $\mathrm{H}_{2} \mathrm{PtCl}_{6}$, respectively. In this way, the wire diameter can be easily controlled by the additive amount of nucleating agents.

\section{Conclusion}

In the present work, the formation process of nickel wires by electroless deposition under a magnetic field was electrochemically investigated. The formation mechanism of nickel wires was proposed on the basis of the electrochemical measurements. The reduction ability of hydrazine oxidation reactions becomes lower at a lower concentration of $\mathrm{NaOH}$, resulting in a slow deposition rate of nickel and realizing the formation of smooth nickel wires. The rate of nickel deposition reaction can also be controlled by the addition of a complexing agent, $\mathrm{Na}_{3} \mathrm{C}_{6} \mathrm{H}_{5} \mathrm{O}_{7}$. The smooth and high-aspect nickel wires are obtained by adjusting a concentration of $\mathrm{Na}_{3} \mathrm{C}_{6} \mathrm{H}_{5} \mathrm{O}_{7}$, and the diameter of nickel wires were controlled from $100 \mathrm{~nm}$ to $370 \mathrm{~nm}$ by the addition of a nucleating agent, $\mathrm{H}_{2} \mathrm{PtCl}_{6}$.

\section{Acknowledgments}

This research was supported by a Grant-in-Aid for JSPS fellows, Grant-in-Aid for Knowledge Cluster Initiative (Kyoto Nanotechnology Cluster), Grant-in-Aid for the Global COE Program (International Center for Integrated Research and Advanced Education in Materials Science), and Grant-in-Aid for Young Scientists (B 20760505), all from the Japan Society for the Promotion of Science, Ministry of Education, Culture, Sports, Science and Technology of Japan. This research was also supported by the Kurata Memorial Hitachi Science and Technology Foundation and Shorai Foundation for Science and Technology.

\section{References}

1. Y. Xia, P. Yang, Y. Sun, Y. Wu, B. Mayers, B. Gates, Y. Yin, F. Kim, and H. Yan, Adv. Mater., 15, 353 (2003).

2. J. I. Martína, J. Nogués, K. Liu, J. L. Vicent, and I. K. Schuller, J. Magn. Magn. Mater., 256, 449 (2003)

3. K. Nielsch, F. Müller, A.-P. Li, and U. Gösele, Adv. Mater., 12, 582 (2000)

4. H. Pan, H. San, C. Poh, Y. Feng, and J. Lin, Nanotechnology, 16, 1559 (2005).

5. J.-H. Lim, A. Rotaru, S.-G. Min, L. Malkinski, and J. B. Wiley, J. Mater. Chem., 20, $9246(2010)$

6. M. Tian, J. Wang, J. Kurtz, T. E. Mallouk, and M. H. W. Chan, Nano Lett., 3, 919 (2003).

7. Y. Fukunaka, M. Motoyama, Y. Konishi, and R. Ishii, Electrochem. Solid-State Lett., 9, C62 (2006).

8. S. Sharma, A. Barman, M. Sharma, L. R. Shelford, V. V. Kruglyak, and R. J. Hicken, Solid State Commun., 149, 1650 (2009).

9. V. V. Sviridov, G. P. Shevchenko, A. S. Susha, and N. A. Diab, J. Phys. Chem., 100, 19632 (1996).

10. S.-H. Wu and D.-H. Chen, J. Colloid Interface Sci., 259, 282 (2003).

11. M. Grzelczak, J. Pérez-Juste, B. Rodríguez-Gonzáles, M. Spasova, I. Barsukov, M. Farle, and L. M. Liz-Marzán, Chem. Mater., 20, 5399 (2008).

12. S. Yagi, H. Nakanishi, E. Matsubara, S. Matsubara, T. Ichitsubo, K. Hosoya, and Y. Matsuba, J. Electrochem. Soc., 155, D474 (2008).

13. S. Yagi, H. Nakanishi, T. Ichitsubo, and E. Matsubara, J. Electrochem. Soc., 156, D321 (2009).

14. S. Yagi, M. Kawamori, and E. Matsubara, Electrochem. Solid-State Lett., 13, E1 (2010).

15. M. D. L. Balela, S. Yagi, and E. Matsubara, Electrochem. Solid-State Lett., 13, D4 (2010).

16. S. Yagi, T. Koyanagi, H. Nakanishi, T. Ichitsubo, and E. Matsubara, J. Electrochem. Soc., 155, D583 (2008).

17. S. Yagi, M. Kawamori, and E. Matsubara, J. Electrochem. Soc., 157, E92 (2010).

18. A. Janshoff, H. J. Galla, and C. Steinem, Angew. Chem. Int. Ed., 39, 4004 (2000).

19 M. Pourbaix, Atlas of Electrochemical Equilibria in Aqueous Solutions, p. 330, Cebelcor, Brüssel (1966).

20. S. Yagi, A. Kawakami, K. Murase, and Y. Awakura, Electrochim Acta, 52, 6041 (2007).

21. O. Younes and E. Gileadi, J. Electrochem. Soc., 149, C100 (2002).

22. G. Viau, P. Toneguzzo, A. Pierrard, O. Acher, F. Fiévet-Vincent, and F. Fiévet, Scr. Mater., 44, 2263 (2001).

23. M. D. L. Balela, S. Yagi, Z. Lockman, A. Aziz, A. V. Amorsolo, and E. Matsubara, J. Electrochem. Soc., 156, E139 (2009). 